\title{
Case report: High-volumetric atypical hemihepatectomy in patient with colorectal cancer with extensive metastatic disease
}

\author{
Olga Sjomina ${ }^{1,2,3 *}$, Jelizaveta Pavlova ${ }^{3}$, Evita Gashenko ${ }^{1,3,4}$, Nadezda Vorobjova $^{5}$ and Armands Sivins ${ }^{2,4,6}$ \\ ${ }^{1}$ Riga East Clinical University Hospital, Riga, Latvia \\ ${ }^{2}$ Institute of Clinical and Preventive Medicine, University of Latvia \\ ${ }^{3}$ Faculty of Medicine, University of Latvia, Riga, Latvia \\ ${ }^{4}$ Department of Research, Riga East University hospital, Riga, Latvia \\ ${ }^{5}$ Faculty of Medicine, Riga Stradins University, Riga, Latvia \\ ${ }^{6}$ Surgical Oncology clinic, Latvia Oncology Centre, Riga, Latvia
}

\begin{abstract}
Hepatic metastasectomy in colorectal cancer is becoming a routine procedure, however the presence of extrahepatic metastatic disease worsens the life expectancy. A high-volumetric hepatic resection in case of multiple liver metastases might be performed after iatrogenic liver hypertrophy aimed to enlarge functional liver volume. Ligation or embolization of portal vein can be done. The outcome of the procedure is significantly improved using newest chemotherapy regimens and biological medications. We report a case with successful combined therapy of a 49 -year-old male with colorectal cancer and bilateral extended metastatic process in liver and lungs.
\end{abstract}

\section{Introduction}

Colorectal cancer is the third most common cancer in men and the second in women worldwide with the highest estimated mortality rates in both sexes in Central and Eastern Europe - 20.3 per 100,000 for men, 11.7 per 100,000 for women. In Latvia, colorectal cancer is the second most common cancer related cause of death after lung cancer [1]. Typically metastases of colorectal cancer are primarily found in liver due to drainage through the portal system. Up to $25 \%$ of patients already have liver metastases at the moment of primary diagnosis and 50 to $70 \%$ eventually develop liver metastatic disease during the course of treatment $[2,3]$.

Survival without treatment in metastatic colorectal cancer is poor-approximately 5 to 9 months [4]. Life expectancy might be prolonged by the hepatic resection, which is thought to be the most effective method of therapy, as it is possible to remove up to $80 \%$ of hepatic parenchymatous tissue. Prognosis after hepatic metastasectomy improves significantly with median survival up to 46 months, according to multiple meta-analyses data [5].

\section{Clinical case}

A 49-year-old male presented with abdominal pain and defecation problems. Colonoscopy examination showed ulcerating tumour $8 \mathrm{~cm}$ over the anal opening, histologically-tubular adenoma, CEA - $28.4 \mathrm{ng} /$ $\mathrm{ml}$, CA 19-9 - 31.6 U/ml. A week later local and systemic dissemination of process was radiologically diagnosed (Figures 1-3).

In the third segment of the right lung a solitary metastasis was found. Clinical diagnosis was as follows - malignant tumour of rectum cT4N+M1 (lungs, hepatic), stage IV. Oncologic concilium decision was to start neoadjuvant chemotherapy with six FOLFOX courses and three courses of bevacizumab. After neoadjuvant chemotherapy was finished, repeated abdominal CT was performed.

Two months after neoadjuvant chemotherapy was finished, patient received anterior resection of rectum and transmesorectal excision with preventive iliostoma. Adjuvant chemotherapy was ordinated with FOLFOX and bevacizumab. Overall, patient got four FOLFOX and three bevacizumab courses. Following adjuvant chemotherapy, hepatic MRI was performed (Figure 4).

Two months after MRI examination first stage of surgical management of liver metastases was done-atypical resection of $\mathrm{Sg} 2, \mathrm{Sg}$ 3, Sg 4a and Sg 4b with following right portal vein branch ligation and hepatoduodenal region lymphadenectomy (Figure 5).

Additionally, cholecystectomy was made during operation. Histologically, malignant cells were found in one of five operation material blocks from liver nodes. After first stage of operation patient received seven FOLFIRI and five bevacizumab courses due to allergic reaction for FOLFOX regimen.

Patient continued to be followed-up until the second stage of hepatectomy (Figure 6).

Correspondence to: Olga Sjomina, Riga East Clinical University Hospital, Riga, Latvia; E-mail: olga_sjomina@inbox.lv

Key words: colorectal cancer; hepatic metastases, atypical hemihepatectomy, portal vein ligation

Received: August 15, 2017; Accepted: September 25, 2017; Published: September 28, 2017 


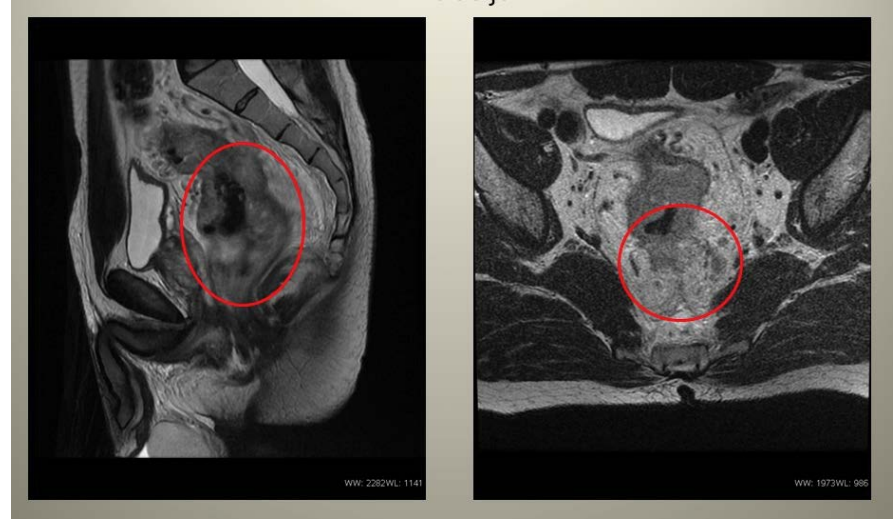

Figure 1. Pelvic MRI showing malignant tumour of rectum with pararectal spread, wide specific regional lymphadenopathy and mesorectal fascia infiltration

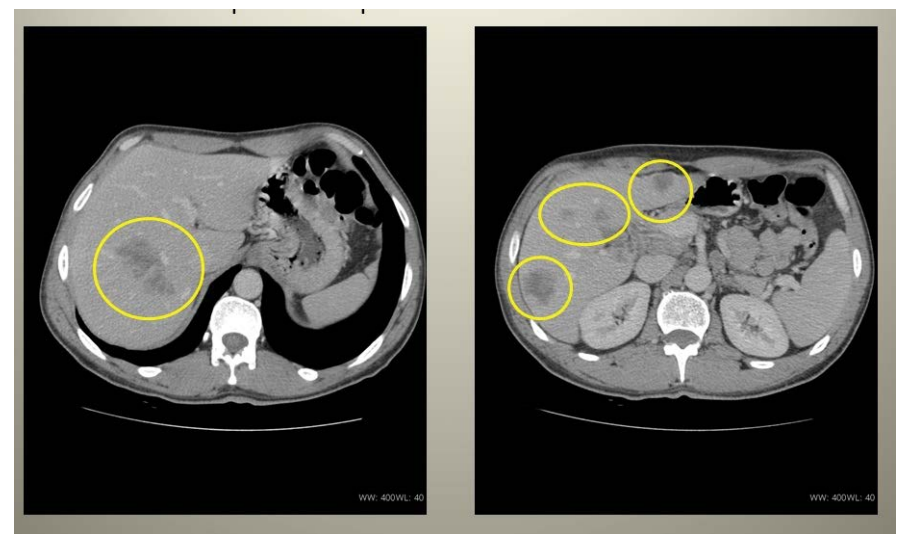

Figure 2. Abdominal CT showing retroperitoneal lymphadenopathy and massive metastatic process in hepatic lobes

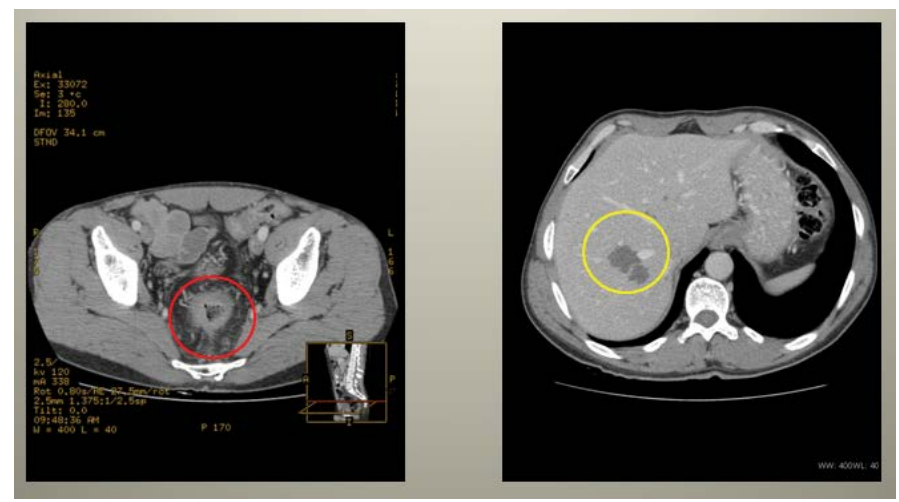

Figure 3. Abdominal CT showing decrease in rectal tumour volume, decrease in local invasion and mesorectal fat tissue invasion, decrease in pathologic regional lymph node number, as well as positive dynamics of metastatic nodes in the liver

Approximately eight months after first stage, the second stage of operation was performed-right hepatectomy (Figure 7).

Intraoperative ultrasonoscopy revealed $\mathrm{Sg} 3$ metastasis $7 \mathrm{~mm}$ in diameter in the hypertrophied left lobe, but due to critically small residual hepatic tissue volume and long operation period, previously planned radiofrequency ablation of new metastasis in the left lobe was cancelled. Histologically-metastatic nodes in liver with patomorphosis stage IV, malignant cells were not found, resection lines were clean. Patient continued receiving adjuvant chemotherapy with three FOLFIRI and three bevacizumab courses with positive dynamics.
Later, right side thoracotomy was done with the third and eighth segment resection. Histologically, metastatic adenocarcinomatous nature of focuses was confirmed. At that moment, management of primary tumour and metastatic focuses was completed. Overall, two years after diagnosis of rectal malignancy, received neoadjuvant and adjuvant chemotherapy and surgical intervention, patient was considered disease-free with no tumour focuses found in CT and MRI examinations (Figure 8).

Already for two years after combined treatment completion patient is followed-up with CT and colonoscopy (CEA and CA 19-9 in reference range). No data about progression of oncologic process are found at the moment.

\section{Discussion}

Earlier metastatic colorectal cancer thought to be incurable disease, however during last decades therapy results improved significantly. Being one of the most common cancer types in the world, it requires rapid improvement of management quality. It is vitally important to use combined therapy even in the late stages of metastatic disease [6].

The liver is the most common localization of metastases, the second place take the lungs-approximately $20 \%$ of patients will develop pulmonic metastases. Previously the main way of treatment of metastatic disease was systemic chemotherapy, however newer regimens of chemotherapeutic agents improved the survival; also newer biological medications brightened the prognosis. FOLFOX in combination with bevacizumab appeared to be highly effective in case of metastatic disease in colorectal cancer [6,7].

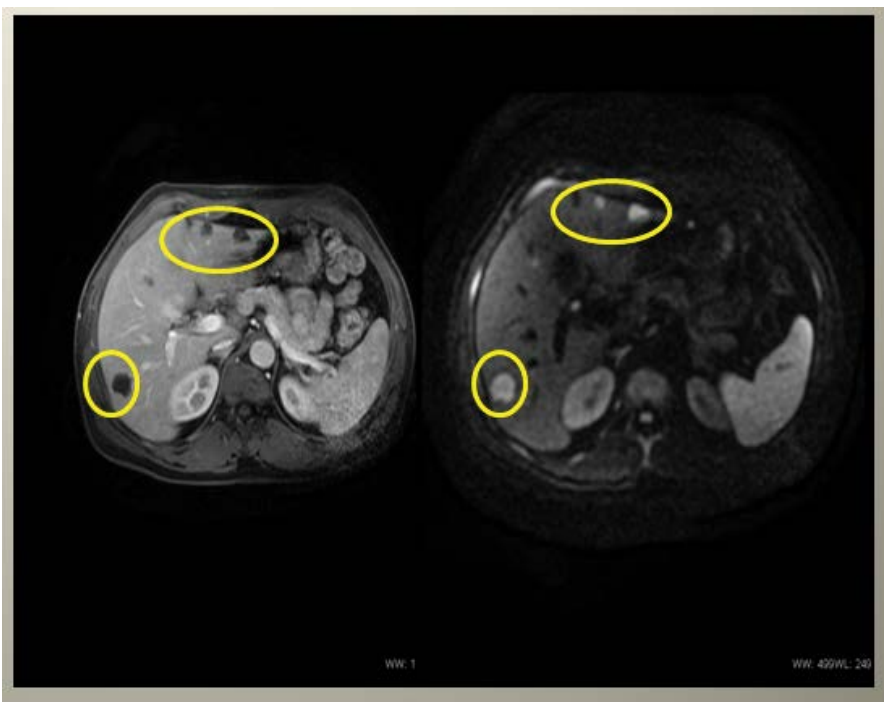

Figure 4. Liver MRI showing positive dynamics of metastatic nodes, some of nodes are not visible in MRI with diffusion anymore, what confirms positive effect of chemotherapy

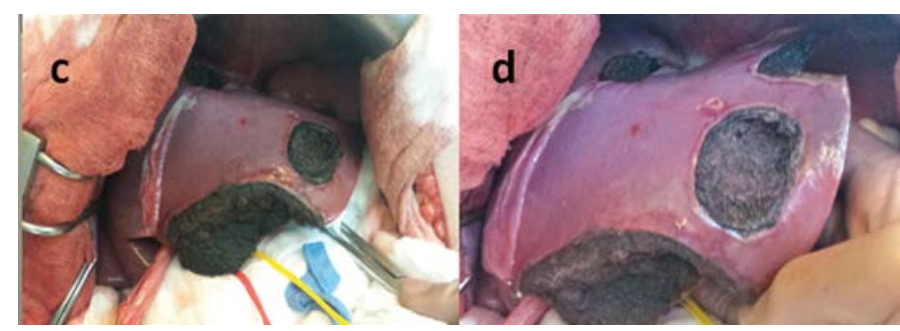

Figure 5. First stage of hepatectomy. Atypical resection of left liver lobe and right portal vein branch ligation 


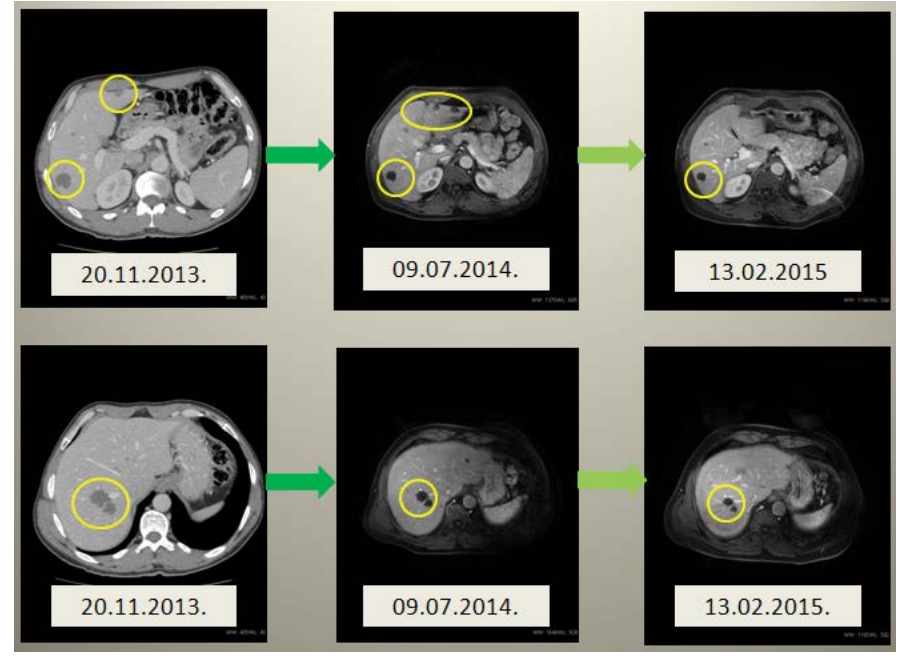

Figure 6. CT and MRI of liver showing dynamic changes in left lobe hypertrophy after right portal vein branch ligation and positive dynamics in metastastatic liver nodes. Active malignant cells were seen only in two metastatic nodes

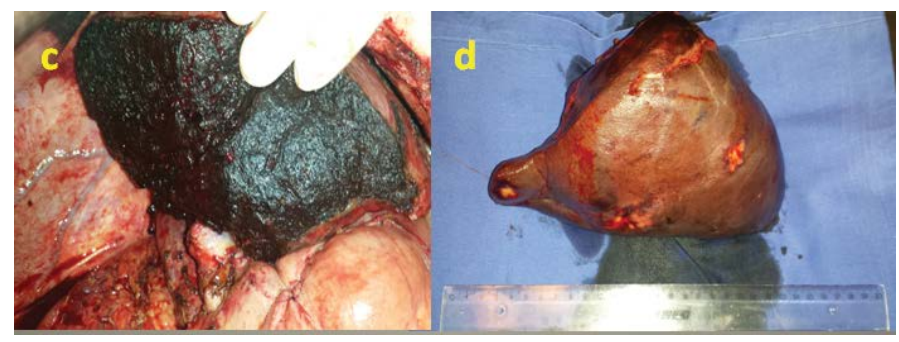

Figure 7. The second stage - right hepatectomy

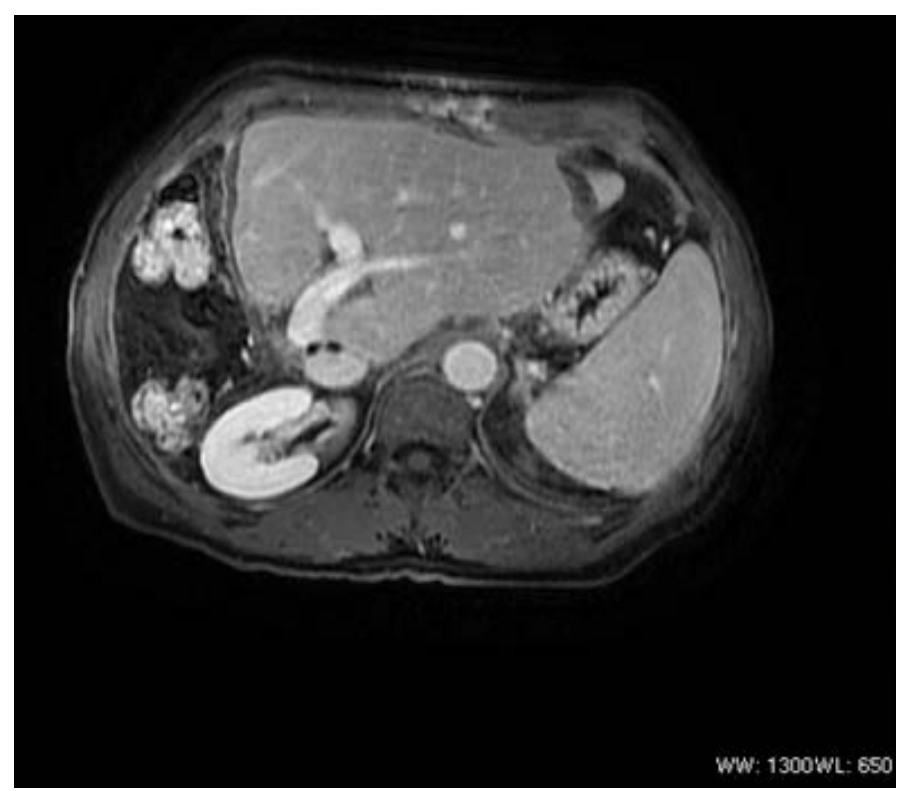

Figure 8. MRI of liver showing organ appearance after successful right hepatectomy and hypertrophy of the left lobe and metastases - free parenchyma

Positive reaction to primary chemotherapy gives the opportunity to perform metastasectomy with prediction of long-time survival. During the last years hepatic metastasectomy is slowly getting used as routine management. The survival rates of patients with potentially resectable metastases used to be six to twelve months; actual 5-year survival rate for resected patients increased up to $39 \%[8,9]$.
The morbidity and mortality after hepatic metastasectomia is usually related to progression of liver failure that depends on the resection volume as well as contribution of coexisting liver disease [1012]. Previous researches in this field provide controversial data about the correlation between the volume of damaged hepatic tissue and life expectancy. Sheele et al. claimed that five and more hepatic metastases negatively impact the result of hepatectomy [13]. However, according to the guidelines, there is no significantly proved adverse influence of the amount or localization of hepatic metastases, if the primary tumour could be radically resected $[11,14]$.

Presence of multiple metastases of colorectal cancer in both hepatic lobes requires a resection of significant liver volume to achieve sufficient results [15]. The possible way of high-volumetric resection with sufficient retention of hepatic function is the iatrogenic partial hypertrophy of preserved lobes. The role of vein ligation was proved by previous researches [16]. In our case ligation of right branch of portal vein was performed. However, according to previous studies it is supposed that portal vein embolization has a significantly better prognosis for hypertrophy of left lobes in comparison with ligation, as the ligation provoked formation of portoportal collaterals $[17,18]$. On the other hand, recent reports proved efficient hypertrophy induced by ligation in two-step hepatectomy $[19,20]$. Although our patient underwent partial left lobe resection and had a remnant node with impossible ablation, the hypertrophy by ligation was evaluated as sufficient, as well as the function of liver at follow-up period is confirmed to be appropriate.

Earlier is was believed that only in case of absent extrahepatic metastases metastasectomy could have significantly positive effect on life expectancy in patients with colorectal cancer. However, nowadays resectable pulmonary metastases are no longer the contraindication for surgical treatment $[6,21-23]$. The follow-up period in our case continues, still after two years after last surgery no metastases were detected neither in the liver, nor in the lungs; CEA also says in reference range.

\section{Conclusion}

The resection of hepatic metastases is the only method to achieve remission. Nowadays metastasectomy in colorectal cancer is becoming a routine, even if extrahepatic resectable metastases are detected. Significant increase of survival rates is supported by newer neoadjuvant and adjuvant chemotherapy regimens, as well as the use of latter-day biological drugs provide recession of primary tumour and metastatic volume up to full response. Even a high-volumetric metastatic damage of liver tissue in selected patients is successfully tolerated after iatrogenically reached hypertrophy of reserved segments. Nevertheless, embolization of portal vein thought to be more effective, the sufficient result can be reached by the ligation.

\section{Conflict of interests}

No conflict of interests was declared.

\section{Acknowledgements}

The authors would like to thank dr. Armand Sivins, Head of Surgical Oncology clinic, of Latvia Oncology Centre, for the permission to use photographs and other data for preparation of this case report.

\section{References}

1. Ferlay J, Soerjomataram I, Dikshit R, Eser S, Mathers C, et al. (2015) Cancer incidence and mortality worldwide: sources, methods and major patterns in GLOBOCAN 2012. Int $J$ Cancer 136: E359-386. [Crossref] 
2. Leonard GD, Brenner B, Kemeny NE (2005) Neoadjuvant chemotherapy before liver resection for patients with unresectable liver metastases from colorectal carcinoma. $J$ Clin Oncol 23: 2038-2048. [Crossref]

3. Kanas GP, Taylor A, Primrose JN, Langeberg WJ, Kelsh MA, et al. (2012) Survival after liver resection in metastatic colorectal cancer: review and meta-analysis of prognostic factors. Clin Epidemiol 4: 283-301. [Crossref]

4. Rothbarth J, van de Velde CJ (2005) Treatment of liver metastases of colorectal cancer. Ann Oncol 16 Suppl 2: ii144-149. [Crossref]

5. Sheth KR, Clary BM (2005) Management of hepatic metastases from colorectal cancer. Clin Colon Rectal Surg 18: 215-223. [Crossref]

6. Mahmoud N, Bullard Dunn K (2010) Metastasectomy for stage IV colorectal cancer. Dis Colon Rectum 53: 1080-1092. [Crossref]

7. Emmanouilides C, Sfakiotaki G, Androulakis N, Kalbakis K, Christophylakis C, et al. (2007) Front-line bevacizumab in combination with oxaliplatin, leucovorin and 5-fluorouracil (FOLFOX) in patients with metastatic colorectal cancer: a multicenter phase II study. BMC Cancer 7: 91. [Crossref]

8. Tomlinson JS, , Jarnagin WR, DeMatteo RP, Fong Y, Kornprat P, et al. (2007) Actual 10 -year survival after resection of colorectal liver metastases defines cure. J Clin Oncol 25: 4575-4580. [Crossref]

9. Jamison RL, Donohue JH, Nagorney DM, Rosen CB, Harmsen WS, et al. (1997) Hepatic resection for metastatic colorectal cancer results in cure for some patients. Arch Surg 132: 505-511. [Crossref]

10. Shoup M, Gonen M, D'Angelica M, Jarnagin WR, DeMatteo RP, et al. (2003) Volumetric analysis predicts hepatic dysfunction in patients undergoing major liver resection. J Gastrointest Surg 7: 325-330. [Crossref]

11. Garden OJ, Rees M, Poston GJ, Mirza D, Saunders M, et al. (2006) Guidelines for resection of colorectal cancer liver metastases. Gut 55 Suppl 3: iii1-8. [Crossref]

12. Soyer P, Roche A, Elias D, Levesque M (1992) Hepatic metastases from colorecta cancer: influence of hepatic volumetric analysis on surgical decision making. Radiology 184: 695-697. [Crossref]

13. Scheele J1, Stang R, Altendorf-Hofmann A, Paul M (1995) Resection of colorectal liver metastases. World J Surg 19: 59-71. [Crossref]
14. Fong Y, Cohen AM, Fortner JG, Enker WE, Turnbull AD, et al. (1997) Liver resection for colorectal metastases. J Clin Oncol 15: 938-946. [Crossref]

15. Capussotti, L (2006) Neoadjuvant chemotherapy and resection for initially irresectable colorectal liver metastases. Br J Surg 93: 1001-1006.

16. Schweizer W, Duda P, Tanner S, Balsiger D, Höflin F, et al. (1995) Experimental atrophy/hypertrophy complex (AHC) of the liver: portal vein, but not bile duct obstruction, is the main driving force for the development of AHC in the rat. $J$ Hepatol 23: 71-78. [Crossref]

17. Denys AL, Abehsera M, Sauvanet A, Sibert A, Belghiti J, et al. (1999) Failure of right portal vein ligation to induce left lobe hypertrophy due to intrahepatic portoportal collaterals: successful treatment with portal vein embolization. AJR Am J Roentgenol 173: 633-635. [Crossref]

18. Broering DC, Hillert C, Krupski G, Fischer L, Mueller L, et al. (2002) Portal vein embolization vs. portal vein ligation for induction of hypertrophy of the future liver remnant. J Gastrointest Surg 6: 905-913. [Crossref]

19. Kianmanesh R, Farges O, Abdalla EK, Sauvanet A, Ruszniewski P, et al. (2003) Right portal vein ligation: a new planned two-step all-surgical approach for complete resection of primary gastrointestinal tumors with multiple bilateral liver metastases. $J$ Am Coll Surg 197: 164-170. [Crossref]

20. Adam R, Miller R, Pitombo M, Wicherts DA, de Haas RJ, et al. (2007) Two-stage hepatectomy approach for initially unresectable colorectal hepatic metastases. Surg Oncol Clin N Am 16: 525-536. [Crossref]

21. Headrick JR, Miller DL, Nagorney DM, Allen MS, Deschamps C, et al. (2001) Surgical treatment of hepatic and pulmonary metastases from colon cancer. Ann Thorac Surg 71: 975-980. [Crossref]

22. Iizasa T, Suzuki M, Yoshida S, Motohashi S, Yasufuku K, et al. (2006) Prediction of prognosis and surgical indications for pulmonary metastasectomy from colorectal cancer. Ann Thorac Surg 821: 254-260. [Crossref]

23. Smith JW, Fortner JG, Burt M (1992) Resection of hepatic and pulmonary metastases from colorectal cancer. Surg Oncol 1: 399-404. [Crossref]

Copyright: (C2017 Sjomina O. This is an open-access article distributed under the terms of the Creative Commons Attribution License, which permits unrestricted use, distribution, and reproduction in any medium, provided the original author and source are credited. 